This item was submitted to Loughborough's Research Repository by the author.

Items in Figshare are protected by copyright, with all rights reserved, unless otherwise indicated.

\title{
An experimental study of gas void fraction in dilute alcohol solutions in annular gap bubble columns using a four-point conductivity probe
}

PLEASE CITE THE PUBLISHED VERSION

http://dx.doi.org/10.1016/j.ces.2011.03.061

PUBLISHER

(C) Elsevier

VERSION

AM (Accepted Manuscript)

LICENCE

CC BY-NC-ND 4.0

\section{REPOSITORY RECORD}

Al-Oufi, Fahd M., Chris D. Rielly, and lain W. Cumming. 2013. "An Experimental Study of Gas Void Fraction in Dilute Alcohol Solutions in Annular Gap Bubble Columns Using a Four-point Conductivity Probe”. figshare. https://hdl.handle.net/2134/11469. 
This item was submitted to Loughborough's Institutional Repository (https://dspace.lboro.ac.uk/) by the author and is made available under the following Creative Commons Licence conditions.

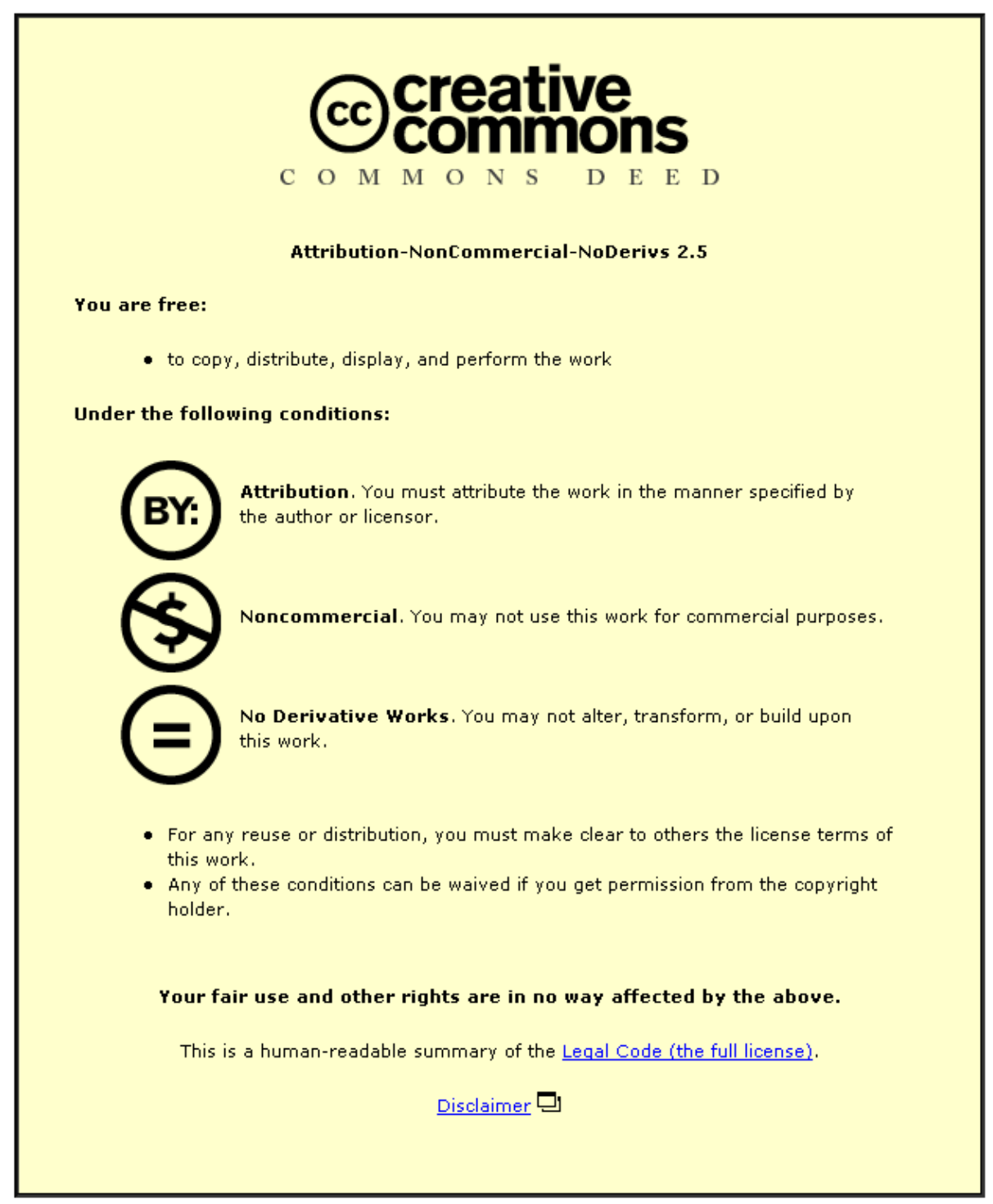

For the full text of this licence, please go to: http://creativecommons.org/licenses/by-nc-nd/2.5/ 


\section{An experimental study of gas void fraction in dilute alcohol solutions in}

annular gap bubble columns using a four-point conductivity probe

Fahd M. Al-Oufi, Prof. Chris D. Rielly ${ }^{*}$ and Dr. lain W. Cumming

Department of Chemical Engineering, Loughborough University, Loughborough, LE11 3TU, UK.

\section{ABSTRACT}

The influence of alcohol concentration on the gas void fraction in open tube and annular gap bubble columns has been investigated using a vertical column with an internal diameter of $0.102 \mathrm{~m}$, containing a range of concentric inner tubes which formed an annular gap; the inner tubes had diameter ratios from $0.25-0.69$. Gas (air) superficial velocities in the range $0.014-0.200 \mathrm{~m} / \mathrm{s}$ were investigated. Tap water and aqueous solutions of ethanol and isopropanol, with concentrations in the range 8 - 300 ppm by mass, were used as the working liquids. Radial profiles of the local void fraction were obtained using a four-point conductivity probe and were crosssectionally averaged to give mean values that were within $12 \%$ of the volumeaveraged gas void fractions obtained from changes in aerated level. The presence of alcohol inhibited the coalescence between the bubbles and consequently increased the mean gas void fraction at a given gas superficial velocity in both the open tube and the annular gap bubble columns. This effect also extended the range of homogeneous bubbly flow and delayed the transition to heterogeneous flow. Moreover, isopropanol results gave slightly higher mean void fractions compared to those for ethanol at the same mass fraction, due to their increased carbon chain length. It was shown that the void fraction profiles in the annular gap bubble column were far from uniform, leading to lower mean void fractions than were obtained in an open tube for the same gas superficial velocity and liquid composition.

Keywords: flow transition, homogeneous flow, void fraction profile, conductivity probe, coalescence inhibition

Corresponding author email: C.D.Rielly@lboro.ac.uk, Tel:+44 (0) 1509 222504, Fax: +44 (0) 1509223923 


\section{INTRODUCTION}

In many bubble column and airlift reactors, the liquid phase consists of a mixture of organic and inorganic compounds, e.g. in the case of bubble column bioreactors, where salts, sugars and metabolic products, such as alcohols and organic acids are present in significant quantities in the culture medium (Schugerl et al., 1977; Jamialahmadi and Muller-Steinhagen, 1992). The addition of alcohol to the liquid phase has also been used to simulate the liquid phase behaviour in coal liquefaction and in bioreactors due to the presence of non-coalescing organic mixtures (Kelkar et al., 1983).

It is well known that the most significant difference between air-water and airaqueous solution systems is that, in the former, bubble coalescence rates are high, whilst, in the latter, the coalescence rates are low (Schugerl et al., 1977). The presence of relatively small amounts of alcohol increases the gas void fraction, $\alpha$, in aqueous solutions in bubble columns (Camaras et al., 1999; Sijacki et al., 2009) by inhibiting coalescence. Alcohols comprise hydrophilic (polar) and hydrophobic (carbon chain) parts, as shown in Figure 1. These substances preferentially accumulate at the air-liquid boundary with the hydrophobic part extending towards the centre of the bubble. The monolayer of adsorbed polar molecules makes the interface more rigid; during bubble rise the adsorbed molecules are swept to the rear of the bubble, producing a surface tension gradient, which is balanced by an increased skin friction drag that can reduce the rise velocity and inhibit coalescence (Albijanic et al. 2007). Zahradnik et al. (1999) studied the effect of $n$-alcohols on the gas void fraction and concluded that the gas void fraction increased with an increase in the length of the carbon chain, for a given gas superficial velocity.

Krishna et al. (2000) studied the effect of the presence of alcohol on the transition between homogeneous and heterogeneous flow in a vertical bubble column. They used a Wallis plot (Wallis, 1969) to predict the regime transition point defined by $\left(j_{g}\right)_{\text {trans }}$ and $\alpha_{\text {trans }}$. The Wallis plot is obtained by plotting the drift-flux velocity $j_{g}(1-\alpha)$, expressed by the Richardson and Zaki (1954) equation against $\alpha$, where:

$$
j_{g}(1-\alpha)=v_{t} \alpha(1-\alpha)^{n}
$$


In eq.(1), $n$ is an empirical exponent and $v_{t}$ is the rise velocity of a single bubble, e.g. for the air-water system in the homogeneous regime, $n=2$ (Krishna et al., 2000) and for the rise velocity, $v_{t}=0.24 \mathrm{~m} / \mathrm{s}$ (Wallis, 1969). The point where the experimental data deviate from eq.(1) is taken to indicate the transition point between regimes. Krishna et al. (2000) commented that the transition point is often difficult to characterise and concluded that data from the air-tap water system clearly deviates from the Richardson and Zaki curve earlier $\left(\alpha_{\text {trans }}=0.12\right)$, than for a $0.1 \%$ ethanol solution $\left(\alpha_{\text {trans }}=0.32\right)$ or a $1 \%$ ethanol solution $\left(\alpha_{\text {trans }}=0.40\right)$. In other words, the void fraction at transition increases with an increase in alcohol concentration.

The majority of previous two-phase studies have focussed on open tubes, but many chemical and nuclear engineering systems involve more complex geometries in separators, fuel bundles and steam generators; annular channels have been found replicate some of the phenomena found in these more complex geometries (Ozar et al, 2008). Annular channels also occur in internal-loop, air-lift bubble columns (albeit with an upward liquid flow); more recent applications include photo-catalytic bubble column reactors containing lamps positioned on their centreline.

Al-Oufi (2006) compared gas void fraction data from annular gap bubble columns (AGBC) with those obtained from an open tube (circular cross-section) bubble column (OTBC). He fitted the Zuber and Findlay (1965) drift-flux model, for two experimental data sets for the OTBC and a AGBC using

$$
\alpha=\frac{j_{g}}{C_{0} j_{g}+v_{t}}
$$

where $C_{0}$ is a distribution parameter, related to the radial distributions of gas and liquid velocity and void fraction, and $v_{t}$ is a parameter close to the bubble rise velocity. Both parameters depend on the radial distributions of gas and liquid velocity and void fraction, as given below

$$
C_{0}=\frac{\left\langle\alpha\left(j_{g}+j_{l}\right)\right\rangle}{\langle\alpha\rangle\left\langle j_{g}+j_{l}\right\rangle}
$$




$$
v_{t}=\frac{\left\langle\alpha j_{g l}\right\rangle}{\langle\alpha\rangle}
$$

where $j_{g l}=j_{g} / \alpha-\left(j_{g}+j_{l}\right)$ is the drift-flux velocity of the gas with respect to the mixture. Al-Oufi (2006) obtained parameters in the range $C_{0}=1.1-2.1$ and $v_{t}=0.15-0.25 \mathrm{~m} / \mathrm{s}$, corresponding to $3-8 \mathrm{~mm}$ diameter bubbles (Shamlou et al,. 1994 and Whalley, 1996); the larger fitted value of $v_{t}$ for the AGBC may indicate that larger bubbles were present than in the OTBC. The distribution parameters, $C_{0}$, for the two data sets were also significantly different and outside the normally expected range of 0.9-1.3 reported by Hibiki and Ishii (2002), but similar to the value of $C_{0}=2.0$ obtained by Hasan and Kabir (1992). This may indicate that the bubble size increases with increasing superficial gas velocity for tap water.

For annular gap columns, Hasan and Kabir (1992) found that $C_{0}$ did not change with the ratio of inner to outer diameters,

$$
\beta=\frac{D_{i}}{D_{o}}
$$

and remained close to the value of 2.0 that they had previously obtained for large diameter pipes $\left(D_{o}>0.1 \mathrm{~m}\right)$. In contrast, Hasan and Kabir (1988 a \& b) found an increase in $\beta$ led to a slight increase in $C_{0}$, but offered no explanation. Furthermore, Hasan and Kabir (1992) found that for annular gap bubble columns, $v_{t}$ remained unchanged from its value in an open tube, which would indicate rather similar bubble sizes in the two cases. Observations of an AGBC in Al-Oufi's (2006) work showed that at low $j_{g}$, small bubbles were produced; increasing $j_{g}$ caused these bubbles to merge and form larger bubbles which destabilised the flow at much lower void fractions and superficial gas velocities than in the OTBC with tap water as the working liquid.

Recently Al-Oufi et al. (2010) compared void fractions in various geometries of AGBC for tap water with measurements from an OTBC. They fitted their data to Zuber and Findlay's (1965) drift flux model, eq.(2) and proposed two main effects: (i) 
the presence of a stream of large bubbles affects the bubble rise velocity, $v_{t}$ and (ii) the changing shape of the local void fraction profiles affects the distribution parameter, $C_{0}$. Their main findings were that the mean void fraction in the AGBC is low compared to the OTBC when operated at the same gas superficial velocity, $j_{g}$. They concluded that the presence of large bubbles in the AGBC is able to destabilise the homogeneous flow, while the transition to heterogeneous flow occurred at lower mean gas void fractions than in an OTBC. They also found that the shapes of the local void fraction profiles were affected by the diameter ratio, $\beta$. Thus, the combination of a large bubble formation near the sparger and changing shapes of the local gas void fraction profile, reduce the mean gas void fraction for a given gas superficial velocity, and lead to an earlier transition to heterogeneous flow than would occur in an OTBC.

The purpose of the current contribution is to extend these comparisons between AGBC and OTBC to systems where coalescence is more likely to be inhibited by the presence of surface active molecules such as alcohols.

\section{EXPERIMENTAL METHODS AND APPARATUS}

\subsection{Bubble columns}

The experimental set-up consisted of a vertical outside column of internal diameter (i.d.) $D_{o}=0.102 \mathrm{~m}$, made of transparent QVF® glass and with a height of $2.25 \mathrm{~m}$; the unaerated liquid level in the column was $1.00 \mathrm{~m}$. Compressed air was injected through a porous plastic sparger which covered the whole of the base of the column. The porous sparger had a permeability of $5.3 \times 10^{-14} \mathrm{~m}^{2}$, with a pore size of around $100 \mu \mathrm{m}$, and produced a uniform distribution of bubbles; no large bubbles and slugs were observed moving up the open column at low $j_{g}$. The compressed air supply was regulated and metered through a rotameter in order to give $j_{g}$ in the range $0.014-0.2 \mathrm{~m} / \mathrm{s}$. Annular gap experiments were conducted by using different inner tube diameters $\left(D_{i}=0.025,0.038,0.051\right.$ and 0.070 m o.d. $)$ placed concentrically inside the outer column; later these are denoted by their diameter ratios, 
$\beta=0.25,0.37,0.50$ and 0.69 , respectively. The inner tubes were sealed and filled with water.

The Richardson \& Zaki (1954), eq.(1), and the drift-flux model, eq.(2), both indicate that the gas superficial velocity is the key variable in determining the void fraction. The annular gap has a smaller cross-sectional area than the open tube and so the gas flow rates were adjusted appropriately to cover the same range of $j_{g}$. Overall gas void fractions (volume averages for the whole column) were obtained by recording the volume change on aeration at a given $j_{g}$, according to

$$
\bar{\alpha}=\frac{V_{g}}{V_{g}+V_{l}}
$$

In practice, height measurements were used in place of volumes and were conveniently read from a scale on the wall of the column. Local void fractions were also measured using a four-point conductivity probe, as is described in $§ 2.2$.

Experiments were conducted in both the OTBC and AGBC and apart from the addition of various alcohols, the experimental conditions and column specifications are described by Al-oufi et al. (2010). The liquid phase used in the experiments consisted of tap water to which ethanol and isopropanol were added in various concentrations. The experiments were carried out using 8-300 ppm by mass ethanol concentration and 300 ppm by mass for isopropanol (see Table 1).

\subsection{Probe design and dimensions}

Impedance methods, using one or more electrodes, have previously been used to measure local void fractions and to study different two-phase flow regimes. The electrical conductance of the gas-liquid region surrounding the tips of the electrodes is measured; when the probe tip is in a bubble there is no conductance, whereas when the probe tip is immersed in liquid there is a high conductance. The probe behaves effectively as a local phase discriminator and the probability (fraction of time) that the probe is immersed in a bubble is commonly assumed to be equal to the void fraction. For example, Herringe and Davis (1976) described methods to analyse data from single-point conductivity probes for gas-liquid flows; Julia et al. (2005) used a single-point optical probe to measure local values of $\alpha$ in a gas-liquid flow and showed detailed analysis of how bubbles are pierced (although the 
detection method is different from conductivity probes, the principles of the analysis are very similar); and Angeli and Hewitt (2000) used this technique to detect flow regimes and measure volume fractions in an oil-water flow. Furthermore, with two or more points to the probe, both the local void fraction and the bubble velocity may be measured; the probe also yields information about the chord length distribution of bubbles intercepted by the probe.

A further development in using the probe technique was introduced by employing a four-point probe: e.g. Revanker and Ishii, 1992; Kim et al., 2001; Mishra et al., 2002. Lucas and Mishra (2005) used such a probe to characterise the flow distribution across the cross section, in swirling, bubbly air-water flow, in terms of the gas bubble mean local axial, radial and tangential velocity components. Although results are not presented here, the four-point probe can provide information about bubble velocity, chord length distributions and shape (e.g. Luther et al., 2004), as well as local void fractions. The four-point probe has advantages over two-point probe, since there is greater probability of interception of a bubble at multiple locations, e.g. bubbles that do not travel axially upward make contact with the probe at different angles, which leads to some interceptions being missed.

Figure 2 illustrates the design and geometry of the four-point probe. In principle, the it operates in a similar way to the two-point probe described in Al-Oufi et al. (2010). The probe was made from four stainless steel acupuncture needles which were around $0.3 \mathrm{~mm}$ in diameter. Each needle tip was able effectively to pierce, with a minimum deformation, an oncoming bubble; this led to a sharp signal response which indicated the passage of a bubble-liquid interface. Each tip was a live (+ve) electrode and the stainless steel tube sheath was used as a common earth electrode for the four sensors. Each acupuncture needle was gold-plated to stabilise the response and to prevent corrosion; they were coated with insulating varnish, but $0.4 \mathrm{~mm}$ was exposed from the very tip of the needle.

Probe 1 ( $p 1$ ) was set to be the reference and was the longest probe. The distances between tip 1 and tips 2, 3 and 4 were $1.63 \mathrm{~mm}, 1.41 \mathrm{~mm}$ and $1.57 \mathrm{~mm}$ respectively. Probes 2, 3 and 4 were fixed at a horizontal distance of $0.5 \mathrm{~mm}$ from $\mathrm{p} 1$, as shown in the bottom view in Figure 2. The probes were connected to a four-channel conductivity meter and the output signals were recorded digitally at $2 \mathrm{kHz}$ using LabVIEW software. The raw voltage data were treated in a MATLAB program to give 
local void fractions. The signal processing algorithm is discussed in Al-Oufi et al. (2010).

The distribution of local void fractions was obtained by traversing the probe across the column diameter for the open tube, or radially across the annular gap, at a height of $0.57 \mathrm{~m}$ above the sparger. It was not possible to measure closer than $7 \mathrm{~mm}$ from the near wall of the column, whereas measurements could be made at a distance of only $4 \mathrm{~mm}$ from the far wall, because of the radius of the bend in the probe body. There is no upper limit on the bubble size detected by the probe, although video studies by Al-Oufi (2011) show that large bubbles often distort as they are pierced by the needle. The sampling frequency of $2 \mathrm{kHz}$ allows detection of bubbles down to 1$2 \mathrm{~mm}$ and chord lengths of this size were recorded (Al-Oufi, 2011). The hydrodynamic error associated with the detection of small bubbles depends on their motion relative to the probe; previous work has estimated that detection of bubbles down to $1-3 \mathrm{~mm}$ diameter is possible, with similar probe dimensions to those used here (Shen et al., 2008).

Mean void fractions $\bar{\alpha}$ were obtained by cross-sectionally averaging the local void fraction measurements, assuming (1) axisymmetric profiles and (2) a nearest neighbour extrapolation of the local void fraction profile to the wall:

$$
\bar{\alpha}=\frac{1}{R_{o}^{2}-R_{i}^{2}} \int_{R_{i}}^{R_{o}} 2 r \alpha(r) d r
$$

Data shown next in Figure 3, for the OTBC, confirm that the profiles are approximately axisymmetric; various schemes to extrapolate the local void fractions to the wall made little or no significant difference to the calculated mean void fraction.

\section{OTBC RESULTS AND DISCUSSION}

\subsection{Effects of alcohol concentration on gas void fraction profiles}

Figure 3 shows the gas void fractions profile obtained by traversing the four-point probe across a diameter of the OTBC at a height of $0.57 \mathrm{~m}$ above the sparger, for tap water and various concentrations of ethanol and isopropanol (IPA). All of the profiles are axisymmetric about $y=0.052 \mathrm{~m}$ on the centre-line of the bubble column, 
justifying the use of eq.(7) to calculate the mean $\bar{\alpha}$. At very low $j_{g}$ (homogeneous flow regime) the results show almost uniform distributions of the local void fraction across the column. At higher gas superficial velocities, in the transition flow regime (typically $j_{g} \approx 0.05 \mathrm{~m} / \mathrm{s}$ in tap water) the mean void fraction increases and the void fraction profiles become increasingly non-uniform. In tap water, the void fraction extrapolated to the wall, $\alpha_{w}$, increases in the homogeneous regime, but then remains constant for $j_{g}>0.1 \mathrm{~m} / \mathrm{s}$. The ratio of the centre-line to wall void fractions, $\alpha_{c} / \alpha_{w}$, also increases significantly, from a value of 1 at low $j_{g}$ (a flat profile) to a value of about 1.6 as shown in Figure 4 for the OTBC with tap water and selected ethanol and IPA concentrations. Thus, the void fraction profiles change shape significantly with increasing $j_{g}$ during the transition from homogeneous (bubbly) flow, but less quickly in the later stages of the transition or heterogeneous flow regimes. In the case of $300 \mathrm{ppm}$ IPA, the void fractions at the wall rise to around $\alpha_{\mathrm{w}} \approx 0.4$ and the ratio $\alpha_{c} / \alpha_{w}$ remains closer to unity, i.e. the wall void fractions are greater for IPA than ethanol, but so also are the centreline void fractions.

The effects of the presence of alcohol concentrations on the void fraction profiles are evident even at 8 ppm of ethanol (Figure $3(b)$ ), where the centre-line void fraction is significantly greater than with tap water (Figure $3(a)$ ). Visually, the bubbles are much smaller in the ethanol solutions. With increasing ethanol concentration, the centre-line void fraction increases, although the wall void fractions remain approximately the same $\left(\alpha_{w}<0.20\right)$. The coalescence suppressing properties of the alcohol solutions allows higher centre-line void fractions to be obtained, without the formation of larger, fast-rising bubbles.

The profiles of Figure $3(\mathrm{~g})$ and $(\mathrm{h})$ indicate a significant increase in gas void fractions for IPA compared to ethanol at $300 \mathrm{ppm}$, over the whole range of $j_{g}$. Maximum void fractions of $\alpha>0.6$ (notably close to the centre-line) are possible because of the increased degree of coalescence inhibition by the longer chain alcohol. The surface tension gradient (with respect to concentration) increases with increasing carbon chain length: ethanol > IPA > n-propanol > n-butanol (Sijacki et al, 
2009). Hence the greater molecular weight alcohol (in this case IPA) provides a stronger effect on two-phase hydrodynamics (Albijanic et al. 2007).

Hibiki and Ishii (2002) fitted their void fraction profiles in an OTBC using a power-law equation:

$$
\frac{\alpha-\alpha_{w}}{\alpha_{c}-\alpha_{w}}=1-\left(\frac{r}{R_{o}}\right)^{z}
$$

where the exponent $z$ defines the shape of the non-dimensionalised profile. They showed that $z$ affects the value of the distribution parameter, $C_{0}$, in the drift-flux model, eq.(2): a higher value of $z$ gives a flatter profile and a $C_{0}$ value closer to unity.

Satisfactory fits of eq.(8) to the measured void fraction profiles are shown by solid lines in Figure 3 (a)-(h), for tap water and the various alcohol concentrations, using $z$ as the only adjustable parameter. The variation of $z$ with $j_{g}$ is shown in Figure 5 . The latter shows that $z$ falls sharply with increasing gas superficial velocity in the homogeneous regime and during the transition, whereas in the early parts of the heterogeneous regime $\left(j_{g}>0.1 \mathrm{~m} / \mathrm{s}\right)$, the void fraction profiles almost collapse onto a single curve, and $z$ decreases much more slowly, levelling off at a value between 1 and 2. Under these conditions, the majority of the bubbles tend to travel in the centre of the column and fewer bubbles travel close to the wall; coalescence is more likely to occur close to the centre-line of the column, giving large, fast-rising bubbles; these are surrounded by small bubbles at the wall in the transition and heterogeneous flow regimes.

There is some scatter in the fitted values of $z$ and Figure 5 shows little difference between the tap water and the low ethanol concentrations; hence the profile shapes are approximately the same in each case and there should be little difference in the distribution parameter $C_{0}$. At the higher ethanol concentrations, slightly lower values of $z$ were obtained than in tap water, at the same $j_{g}$.

\subsection{Effects of alcohol concentration on mean gas void fractions}

Volume mean void fractions obtained in tap water and various ethanol concentrations in an OTBC are shown in Figure 6; these data were obtained by 
measuring the changes in the aerated level and applying eq.(6). At lower gas superficial velocities $\left(j_{g}<0.05 \mathrm{~m} / \mathrm{s}\right)$ there was not much difference in void fraction for the various ethanol concentrations; the void fraction is too low $(\bar{\alpha}<0.2)$ for significant coalescence effects to be important, even in tap water. However for $j_{g}>0.05 \mathrm{~m} / \mathrm{s}$ even the smallest ethanol concentration of $8 \mathrm{ppm}$ gave significantly higher mean void fractions, compared to the tap water experiments. The addition of alcohol decreases the surface tension of the solution and suppresses coalescence, as described in section 1, resulting in smaller bubbles than in tap water systems. With increasing ethanol concentration, Figure 6 shows that the effect is enhanced and very high void fractions are obtained with values about $150 \%$ of those in tap water. Furthermore the homogeneous regime appears to be extended to greater $j_{g}$ and the transition to heterogeneous flow occurs later (this will be analysed further in §3.3). Similar results for the presence of alcohol on mean void fractions in open tube bubble columns were reported by previous workers: e.g. Krishna et al. (2000).

Figure 7 compares the measured mean void fractions for the ethanol and isopropanol aqueous solutions at $300 \mathrm{ppm}$. Two sets of data are shown for each solution: (1) a volume-averaged void fraction measured from the changes in aerated level (filled symbols) and (2) a cross-sectionally averaged void fraction from probe 1 (p1) of the four-point conductivity probe (open symbols). The latter makes use of the axisymmetric void fraction profiles to calculate the mean value. These two mean void fractions will only be equal if there are no axial gradients in the bubble column, which is the case here (Al-Oufi, 2011) since the column aspect ratio is $H / D_{o}>10$ and hence end effects should negligible. At low $j_{g}<0.06 \mathrm{~m} / \mathrm{s}$, the void fractions obtained using the probe, were slightly larger than the values obtained using the aerated level method; at higher $j_{g}$ the mean void fraction were underestimated by a maximum of $12 \%$ by the conductivity probe. The latter is due to the smallest bubbles not being intercepted by the needle tips and their contribution being missed to the mean void fraction. In all cases reported here the difference between the two methods is small, confirming that conductivity probes provide an accurate measurement, even in the presence of the small bubbles obtained with the alcohol solutions. 
Figure 7 shows that the 300 ppm IPA solution gives higher mean void fractions compared to the $300 \mathrm{ppm}$ ethanol solution, for both measurement methods and over the whole range of $j_{g}$ studied. This effect is also evident in the profiles plots of Figure $3(\mathrm{~g})$ and $(\mathrm{h})$, where the local void fractions are always greater for the IPA case. In contrast, Figure 6, shows little effect of ethanol concentration on the mean void fraction in the homogeneous regime. However, Sijacki et al. (2009) show that the surface tension gradient for IPA is around three times greater than that for ethanol and hence the greater molecular weight alcohol can be expected to have a much more significant effect on the bubble rise velocity and coalescence immediately above the sparger. These observations are similar to the findings of Zahradnik et al. (1999) for the effect of carbon chain length on the mean void fraction. Thus the hypothesis is that IPA solution has a steeper surface tension gradient with respect to concentration than the ethanol solution and hence the effect on void fraction is more significant.

\subsection{Effects of alcohol concentration on flow regime transitions}

Krishna et al. (2000) proposed the use of a Wallis plot (Wallis, 1969) to obtain information about the gas superficial velocity, $\left(j_{g}\right)_{\text {trans }}$ and void fraction $\alpha_{\text {trans }}$ marking the start of the transition from homogeneous to heterogeneous two-phase flow. Figure 8 shows the drift-flux velocity $j_{g}(1-\alpha)$ plotted against $\alpha$, which was measured by the aerated level method. The smooth curve represents Richardson and Zaki's (1954) eq.(1), which is assumed to represent behaviour in the homogeneous bubbly flow regime and here uses $n=2$ (Krishna et al., 2000) and $v_{t}=0.24 \mathrm{~m} / \mathrm{s}$ (Wallis, 1969). The data fall close to the Richardson and Zaki curve at low gas superficial velocities, indicating that indeed they fall within the homogeneous bubbly flow regime. The points where the data deviate from the curve are taken to indicate the flow regime transition points, giving $\left(j_{g}\right)_{\text {trans }}$ and $\alpha_{\text {trans }}$. Krishna et al. (2000) noted that it can be difficult to distinguish between the transition points for low alcohol concentrations. However, the largest ethanol concentration (300 ppm) clearly deviates from the Richardson and Zaki curve at much higher values of $\left(j_{g}\right)_{\text {trans }}=0.06 \mathrm{~m} / \mathrm{s}$ and $\alpha_{\text {trans }}=0.58$, compared with the tap water experiments, 
where $\left(j_{g}\right)_{\text {trans }}=0.048 \mathrm{~m} / \mathrm{s}$ and $\alpha_{\text {trans }}=0.26$. Table 2 summarises the transition points obtained from Figure 9 for experiments using tap water and various ethanol concentrations in an OTBC. There is a consistent trend of the transition point moving to higher values of $\left(j_{g}\right)_{\text {trans }}$ and $\alpha_{\text {trans }}$ with increasing ethanol concentration (similar effects are found with IPA). Thus, the inhibition of coalescence by the adsorption of ethanol molecules at the air-water interface extends the homogeneous flow regime so that it remains stable at remarkably high void fractions, in agreement with the preliminary conclusions drawn from Figure 6.

\section{AGBC RESULTS AND DISCUSSION}

\subsection{Effects of ethanol concentration on gas void fraction profiles}

Figure 9 shows the radial void fraction profiles for the four annular gap geometries that were studied with $300 \mathrm{ppm}$ ethanol; the centre-line of the annular gap at $r=\left(R_{i}+R_{o}\right) / 2$ is also marked for reference, where $R_{i}$ and $R_{o}$ are the inside and outside column radii, respectively. Similar trends were observed compared to the OTBC: at low gas superficial velocities, the void fraction profiles are almost flat, but become increasingly more non-uniform with increasing $j_{g}$; at higher gas superficial velocities, the profile shape becomes almost independent of $j_{g}$. Unlike the OTBC, the $\alpha$ profiles in the annular gap are not symmetric about the centre-line and the void fraction maximum is displaced significantly towards the inner wall. With increasing diameter ratios, $\beta=D_{i} / D_{0}=R_{i} / R_{0}$, the maximum moves closer to the inner wall of the annular gap and the maximum gas hold-up increases; the same effect was reported by Al-Oufi et al. (2010) for tap water systems in the same geometries of AGBC. The data shown in Figure 9 suggest that there is a high void fraction and a high velocity gas stream that flows preferentially up the inner wall of the annular gap; in contrast, close to the outer wall of the annular gap, the void fraction is rather low and comparable to the values of $\alpha_{w}$ obtained in the OTBC. Moreover, there was no visual evidence of a strong down-flow region near the outer wall, which would have made the probe readings less reliable. 
Ozar et al. (2008) measured and correlated void fraction profiles in annular gaps, albeit with a very much smaller outer column $(0.038 \mathrm{~m})$ and over very different ranges of gas superficial velocities $(0.15-3.86 \mathrm{~m} / \mathrm{s})$ to those studied here. Furthermore, their experiments involved large upward liquid superficial velocities $(1.11-2.00 \mathrm{~m} / \mathrm{s})$. They proposed power-law equations to represent the void fraction profiles according to:

$$
\frac{\alpha}{\langle\alpha\rangle}=\frac{z+1}{z}\left(1-\left|1-\frac{2\left(r-R_{i}\right)}{R_{o}-R_{i}}\right|^{z}\right)
$$

and showed that the distribution parameter, $C_{0}$, was related to the exponent, $z$ using eq.(3). The effect of increasing $z$ in eq.(9) is to flatten the void fraction profile, but, it always remains symmetric about the centre-line of the channel. Furthermore, eq.(9) predicts that the void fractions at the walls of the annular gap are zero. Thus the data in Figure 9 cannot be successfully correlated by an expression of the form of eq.(9) since they are (i) asymmetric about the centre-line and clearly the shape of the profile changes with the geometry of the annular gap and (ii) the inner wall void fraction is non-zero and close to the maximum value in the radial profile. Ozar et al. (2008) considered only one gap geometry with $\beta=0.50$ and, despite their use of eq.(9), their profiles also show some asymmetry, with the maximum being displaced toward the inner wall, but not to the extent shown in Figure 9.

The profiles of Figure 9 indicate that $C_{0}$ is likely to increase above unity, with increasing diameter ratio, $\beta$. In that case, eq.(2) for Zuber and Findlay's (1965) driftflux model indicates that the mean void fraction should decrease with increasing values of $\beta$ for a given gas superficial velocity. In other words, the mean gas hold falls when the diameter of the inner column increases, which is what has been observed experimentally by Al-Oufi et al. (2010) for tap water and will be discussed next for these alcohol solutions.

\subsection{Mean void fractions with 300 ppm IPA}

Al-Oufi et al. (2010) reported data for mean void fractions in tap water in various geometries of AGBC. They showed that $\bar{\alpha}$ decreased with increasing diameter ratio, $\beta$, for the annular gap, because of (i) the changes in the radial void fraction 
profile (described in the previous section) and (ii) an earlier transition to heterogeneous flow. Figure 10 shows similar effects for the 300 ppm IPA solution for mean void fractions obtained using changes in the aerated level method (similar conclusions may be drawn from $\bar{\alpha}$ measurements from the conductivity method). At low $j_{g}$ in the homogeneous flow regime the differences in void fraction are small, but with increasing gas superficial velocity the mean void fractions for the larger $\beta$ AGBCs fall further below the OTBC values.

Parameters, $C_{0}$ and $v_{t}$ obtained from Zuber and Findlay's (1965) drift-flux model of eq.(2) by fitting $j_{g} / \bar{\alpha}$ against $j_{g}$ are shown in Figure 11 for the four diameter ratios of the AGBC and the OTBC $(\beta=0)$ for 300 ppm ethanol and IPA solutions. The parameter $v_{t}$ remains approximately constant, indicating the mean bubble size is not changing much with annular gap geometry. In contrast $C_{0}$ increase significantly from close to unity to about 1.8 with increasing $\beta$, which is consistent with (i) the changes shown in Figure 9 for the void profile profiles and (ii) the effects of $\beta$ on the mean void fraction. If $v_{t}$ is interpreted as a single bubble rise velocity, then a value of 0.10 to $0.14 \mathrm{~m} / \mathrm{s}$ would correspond to bubbles of equivalent diameter of about $d_{e}=1.5 \mathrm{~mm}$ (Clift et al., 2005) indicating considerably smaller sizes than would be found in tap water.

Thus the effect of changing gap geometry on the distribution parameter for the AGBCs, previously reported for tap water (Al-Oufi et al., 2010) has been confirmed for these alcohol solutions. However, the inference from the fitted values of $v_{t}$ is that the bubble size remains small even in the annular gap geometries.

\subsection{Flow regime transitions}

Al-Oufi et al. (2010) used Wallis plots to show that the transition point $\alpha_{\text {trans }}$ decreased slightly with increasing diameter ratio $\beta$ for various AGBC geometries with tap water (see Table 3). They postulated that the presence of the inner tube generated larger bubbles which destabilise the homogeneous flow at lower gas superficial velocity and mean void fraction than for the OTBC. A Wallis plot for the 300 ppm IPA solutions in the OTBC and AGBCs is shown in Figure 12 and the 
transition points for different inner tube ratios are listed in Table 3. The effect of changing the inner tube diameter appears to be more significant with 300 ppm IPA than for tap water, but the data do not agree so well with the Richardson and Zaki curve in Figure 12 and hence the values of $\alpha_{\text {trans }}$ are subject to some error (no single values of $n$ and $v_{t}$ for eq.(1) were found to be suitable). Similar analyses (not shown here) for $300 \mathrm{ppm}$ ethanol are also summarised in Table 3, where the transition

points $\left(j_{g}\right)_{\text {trans }}$ and $\alpha_{\text {trans }}$ are close to the values for IPA. Both alcohols show the same effects as has been observed for tap water, i.e. the homogeneous flow is destabilised at a lower gas superficial velocity as the annular gap width is reduced. The presence of the alcohols extends the homogeneous flow regime to higher $j_{g}$ than for the tap water system for each diameter ratio, but the effect is not as dramatic as in the OTBC.

\section{CONCLUSIONS}

Measurements of local void fractions in an OTBC showed that the profiles changed shape with increasing gas superficial velocity, particularly in the homogeneous and early transition regimes. The changing shapes of the profiles were analysed by fitting Hibiki and Ishii's (2002) radial distribution to the data, demonstrating that these effects would alter the value of distribution parameter $C_{0}$ in the homogeneous regime. With the alcohol solutions, there were similar changes to the void fraction profiles and very large centre-line values could obtained without significant bubble coalescence. Mean void fractions were up to $150 \%$ of the tap water values with low concentrations of ethanol or IPA and even the smallest addition of $8 \mathrm{ppm}$ ethanol produced a noticeable effect on coalescence. IPA had a stronger effect on the twophase hydrodynamics in the OTBC, because of its greater carbon chain length than ethanol. Transition point void fractions and gas superficial velocities were obtained which demonstrated that the OTBC homogeneous flow regime could be significantly extended with small additions of ethanol or IPA; the transition was delayed until the void fraction exceeded $\alpha>0.6$ in the highest alcohol concentrations. 
For the $A G B C$, an increasing diameter ratio $\beta$ (narrower annular gap) led to the local void fraction profiles becoming increasingly non-uniform and asymmetric. Although existing profile models could not be satisfactorily fitted to the local void fraction data, it was evident that these shape changes would affect the distribution parameter $C_{0}$ in the drift-flux model. This was confirmed by fitting values of $C_{0}$ and $v_{t}$ to mean void fraction results over a range of gas superficial velocities for the alcohol solutions: $C_{0}$ increased with an increasing diameter ratio, reflecting the reduction in the mean gas void fraction predicted by the drift-flux model, which was consistent with the changing profile shapes. The latter is in agreement with findings previously reported for tap water (Al-Oufi et al., 2010). However, with the alcohol solutions there was no strong evidence of a change of bubble size with changing diameter ratio $\beta$. Analysis also showed that there was an earlier transition to heterogeneous flow for an AGBC than would occur in an OTBC. The presence of surface active molecules such as alcohols led to transition at higher values of the void fraction, but the effect was not as strong as in the OTBC. 


\section{NOMENCLATURE}

$C_{0}$ distribution parameter

$d_{e} \quad$ bubble equivalent diameter $(\mathrm{m})$

$D_{i} \quad$ diameter of the inside column (m)

$D_{0} \quad$ diameter of the outside column $(\mathrm{m})$

$H$ aerated level $(\mathrm{m})$

$j_{g} \quad$ gas superficial velocity $(\mathrm{m} / \mathrm{s})$

$\left(j_{g}\right)_{\text {trans }}$ transition gas superficial velocity $(\mathrm{m} / \mathrm{s})$

$j_{l} \quad$ liquid superficial velocity $(\mathrm{m} / \mathrm{s})$

$n \quad$ empirical exponent in eq.(1)

$r \quad$ radius $(\mathrm{m})$

$R_{i} \quad$ radius of the inside column $(\mathrm{m})$

$R_{o} \quad$ radius of the outside column $(\mathrm{m})$

$V_{g} \quad$ volume of gas $\left(\mathrm{m}^{3}\right)$

$V_{l} \quad$ volume of liquid $\left(\mathrm{m}^{3}\right)$

$v_{t} \quad$ single bubble rise velocity used $(\mathrm{m} / \mathrm{s})$

$z \quad$ empirical exponent in eq.(8) and eq.(9)

\section{Greek}

$\alpha \quad$ gas void fraction (-)

$\alpha_{c} \quad$ centre-line gas void fraction (-)

$\alpha_{\text {trans }}$ regime transition point (-)

$\alpha_{w} \quad$ wall gas void fraction (-)

$\beta \quad$ diameter ratio $D_{i} / D_{o}$ of the annular gap column (-)

\section{Abbreviations}

OTBC open tube bubble column

AGBC annular gap bubble column 


\section{REFERENCES}

Albijanic, B., Havran,V. Petrovic, D. Lj., Duric M., and Tekic, M. N., 2007 Hydrodynamics and mass transfer in a draft tube airlift reactor with dilute alcohol solutions, A.I.Ch.E.J., 53(11), 2897-2904.

Al-Oufi, F. M., 2006. Measuring void fraction in gas-liquid flow using conductivity, MSc Dissertation, Loughborough University, UK.

Al-Oufi, F. M., Cumming, I. W. and Rielly, C. D., 2010. Destabilisation of homogeneous bubbly flow in an annular gap bubble column. The Canadian J. of Chem. Eng., 88(4), 482-490.

Al-Oufi, F.M., 2011, An investigation of gas void fraction and transition conditions for two-phase flow in an annular gap bubble column, PhD thesis, Loughborough University, UK

Angeli, P. and Hewitt, G.F., 2000. Flow structure in horizontal oil-water flow. Int. J. of Multiphase Flow, 26(7), 1117-1140.

Camarasa, E., Vial, C., Poncin, S., Wild, G., Midoux, N. and Bouillard, J., 1999. Influence of coalescence behaviour of the liquid and of gas sparging on hydrodynamics and bubble characteristics in a bubble column. Chem. Eng. and Processing, 38(4-6), 329-344.

Clift, R., Grace, J.R. and Weber, M.E., 2005. Bubbles, Drops and Particles. Second edition. Academic Press, New York.

Hasan, A.R. and Kabir, C.S., 1988. A study of multiphase flow behavior in vertical oil wells. S.P.E. Production Engineering, 3(a), 263-272.

Hasan, A.R. and Kabir, C.S., 1988. Predicting multiphase flow behavior in a deviated well. S.P.E. Production Engineering, 3(b), 474-482.

Hasan, A.R. and Kabir, C.S., 1992. Two-phase flow in vertical and inclined annuli. Int. J. of Multiphase Flow, 18(2), 279-293.

Herringe, R.A. and Davis, M.R., 1976. Structural development of gas-liquid mixture flows. J. of Fluid Mechanics, 73, 97-123.

Hibiki, T. and Ishii, M., 2002. Distribution parameter and drift velocity of drift-flux model in bubbly flow. Int. J. of Heat and Mass Transfer, 45(4), 707-721. 
Jamialahmadi, M. and Müuller-Steinhagen, H., 1992. Effect of alcohol, organic acid and potassium chloride concentration on bubble size, bubble rise velocity and gas hold- up in bubble columns. The Chem. Eng. J., 50(1), 47-56.

Julia, J., Harteveld, W., Mudde, R. and Van den Akker, H., 2005. On the accuracy of the void fraction measurements using optical probes in bubbly flows. Rev. of Scientific Instruments, 76(3), 035103-035103-13.

Kelkar, B.G., Godbole, S.P., Honath, M.F., Shah, Y.T., Carr, N.L. and Deckwer, W., 1983. Effect of addition of alcohols on gas holdup and backmixing in bubble columns. A.I.Ch.E. Journal, 29(3), 361-369.

Kim, S., FU, X.Y., Wang, X. and Ishii, M., 2001. Study on interfacial structures in slug flows using a miniaturized four-sensor conductivity probe. Nuc. Eng. and Design, 204(1-3), 45-55.

Krishna, R., Dreher, A.J. and Urseanu, M.I., 2000. Influence of alcohol addition on gas hold-up in bubble columns: Development of a scale up model. Int. Commun. in Heat and Mass Transfer, 27(4), 465-472.

Krishna, R., Urseanu, M.I. and Dreher, A.J., 2000. Gas hold-up in bubble columns: influence of alcohol addition versus operation at elevated pressures. Chem. Eng. and Processing, 39(4), 371-378.

Lucas, G.P. and Mishra, R., 2005. Measurement of bubble velocity components in a swirling gas-liquid pipe flow using a local four-sensor conductance probe. Meas. Sci. \& Tech., 16(3), 749-758.

Luther, S., Rensen, J. and Guet, S., 2004. Bubble aspect ratio and velocity measurement using a four-point fibre-optical probe. Expts. in Fluids, 36(2), 326-333.

Mishra, R., Lucas, G. and Kieckhoefer, H., 2002. A model for obtaining the velocity vectors of spherical droplets in multiphase flows from measurements using an orthogonal four-sensor probe. Meas. Sci. and Tech., 13(9), 1488-1498.

Ozar, B., Jeong, J., Dixit, A., Juliá, J., Hibiki, T. and Ishii, M. 2008. Flow structure of gas-liquid two-phase flow in an annulus, Chem. Eng. Sci., 63, 3998 - 4011.

Revankar, S.T. and Ishii, M., 1992. Local interfacial area measurement in bubbly flow. Int. J. of Heat and Mass Transfer, 35(4), 913-925. 
Richardson, J.F. and Zaki, W.N., 1954. Sedimentation and fluidisation. Trans. I. Chem. E., 32, 35-53.

Schugerl, K., Lucke, J. and Oels, U., 1977. Bubble Column Bioreactors. Adv. Biochem. Eng., 7, 1-84.

Shen, X., Mishima, K. and Nakamura, H., (2008). Error reduction, evaluation and correction for the intrusive optical four-sensor probe measurement in multidimensional two-phase flow, Int. J. of Heat and Mass Transfer, 51(3-4), 882-895

Shamlou, P., Pollard D., Ison A., and Lilly M., 1994. Gas holdup and liquid circulation rate in concentric-tube airlift bioreactors. Chem. Eng. Sci., 49(3), 303-312.

Sijacki, I., Colovic, R., Petrovic, D. Tekic, D. and Duric, M., 2009. Diluted alcohol solutions in bubble columns and draft tube airlift reactors with a single orifice sparger: experiments and simple correlations. J. Chem. Tech. and Biotech., 85(1), 39-49.

Wallis, G.B., 1969. One-dimensional two-phase flow. New York: McGraw-Hill.

Whalley, P.B., 1996. Two-phase flow and heat transfer. Oxford: Oxford University Press.

Zahradnik, J., Kuncova, M. and Fialova M., 1999 .The effect of surface active additives on bubble coalescence and gas holdup in viscous aerated batches. Chem. Eng. Sci., 54, 2401-2408.

Zuber, N. and Findlay, J. A., 1965. Average volumetric concentration in two-phase flow system. J. Heat Transf., 87, 453-468. 


\section{Table and figure captions}

Table 1 Alcohol concentrations (by mass) used in the study

Table 2 Summary of $\alpha_{\text {trans }}$ and $\left(j_{g}\right)_{\text {trans }}$ for tap water and alcohol aqueous solutions in an OTBC

Table 3 Transition point $\alpha_{\text {trans }}$ and $\left(j_{g}\right)_{\text {trans }}$ for tap water and alcohol aqueous solutions in the OTBC and AGBC

Figure 1 Adsorption of alcohol molecules (comprising hydrophilic and hydrophobic parts) at the air-water interface to form a non-coalescing solution.

Figure $2 \mathrm{~A}$ schematic of the four-point conductivity probe (not to scale); the inset shows the four-point conductivity probe alongside to some typical bubbles.

Figure 3 Profiles of the local gas void fraction with the distance from the wall, $y$, across a diameter of the open tube bubble column, using a porous sparger, tap water and assorted alcohol concentrations. The legend gives the gas superficial velocity.

Figure 4 The ratio of the centreline void fraction, $\alpha_{c}$, to the wall void fraction, $\alpha_{w}$, in the OTBC.

Figure 5 Hibiki and Ishii's (2002) profile exponent $z$ with respect to $j_{g}$ : (a) the tap water and various ethanol concentrations and (b) various ethanol alcohol concentrations and 300 ppm IPA; the experiments were conducted in the OTBC.

Figure 6 Mean gas void fractions in the OTBC for various ethanol concentrations compared to tap water results, obtained using the aerated level method.

Figure 7 Mean void fractions of ethanol and IPA concentrations at $300 \mathrm{ppm}$, using the aerated level (filled symbols) and conductivity probe methods (open symbols).

Figure 8 Wallis plot to determine the transition parameters, $\alpha_{\text {trans }}$ and $\left(j_{g}\right)_{\text {trans }}$ for different ethanol concentrations in an OTBC. 
Figure 9 Radial profiles of local gas void fraction for different geometries of the AGBC for $300 \mathrm{ppm}$ ethanol. The vertical dashed line indicates the centreline of the annulus. The legend gives the gas superficial velocity $(\mathrm{m} / \mathrm{s})$.

Figure 10 The effects of the AGBC geometry on the mean gas void fraction in a comparison to the OTBC results for $300 \mathrm{ppm}$ IPA, using the aerated level method.

Figure 11 The distribution parameter and the rise velocity with respect to the AGBC diameter ratio for $300 \mathrm{ppm}$ ethanol solution.

Figure 12 Wallis plot to determine the transition point, $\left(j_{g}\right)_{\text {trans }}$ and $\alpha_{\text {trans }}$ for $300 \mathrm{ppm}$ IPA in the OTBC and various geometries of AGBC. 


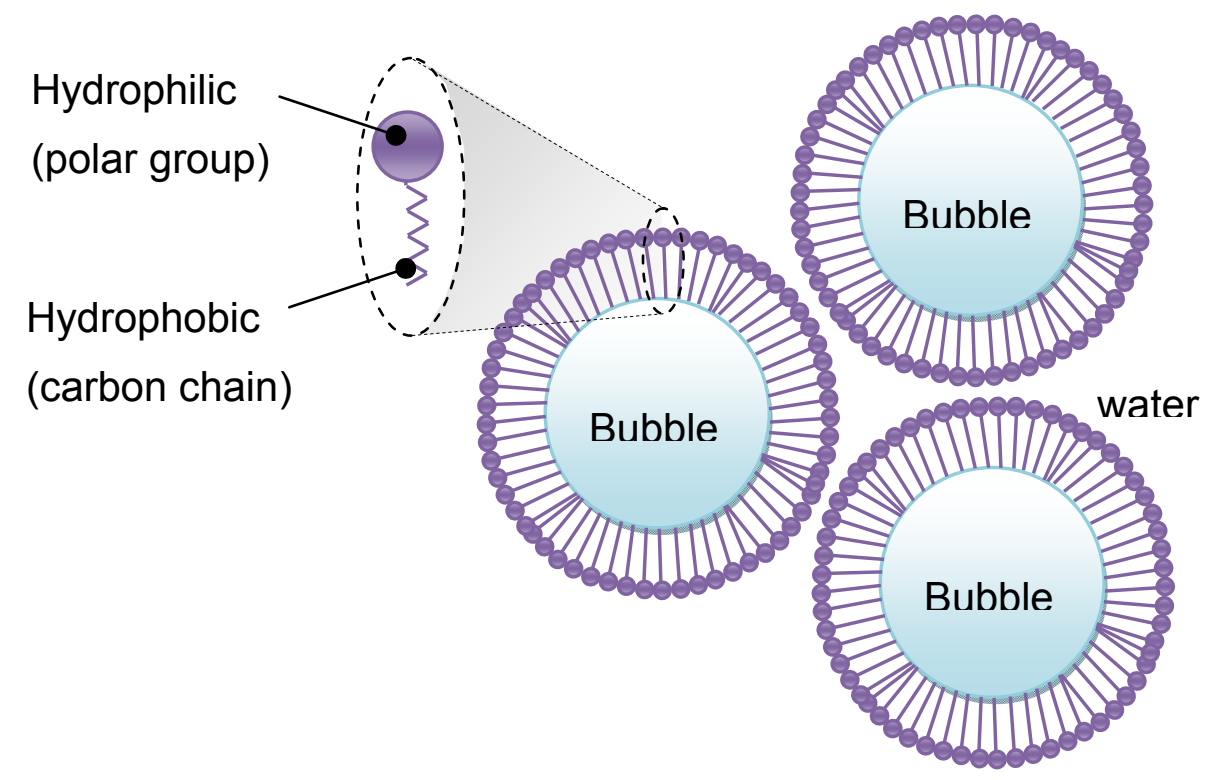

Figure 1 Adsorption of alcohol molecules (comprising hydrophilic and hydrophobic parts) at the air-water interface to form a non-coalescing solution.

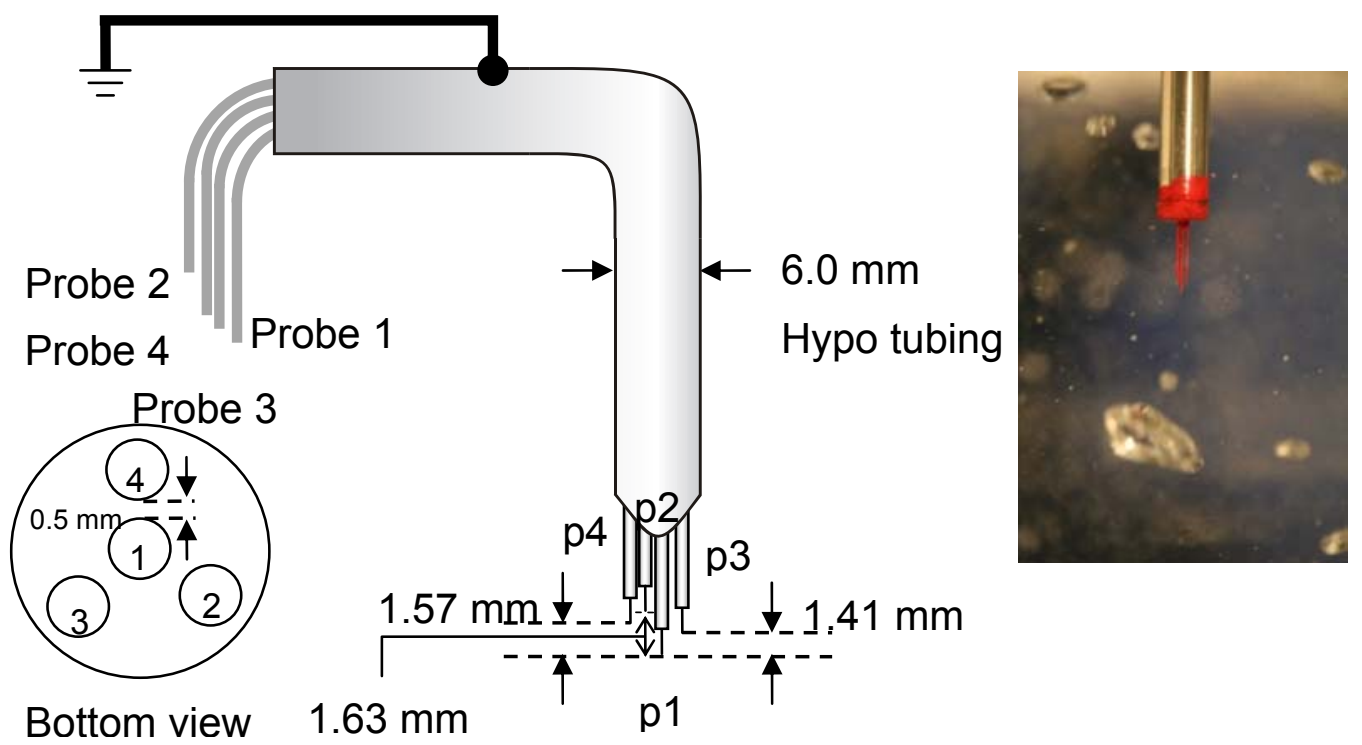

Figure 2 A schematic of the four-point conductivity probe (not to scale); the inset shows the four-point conductivity probe alongside to some typical bubbles. 

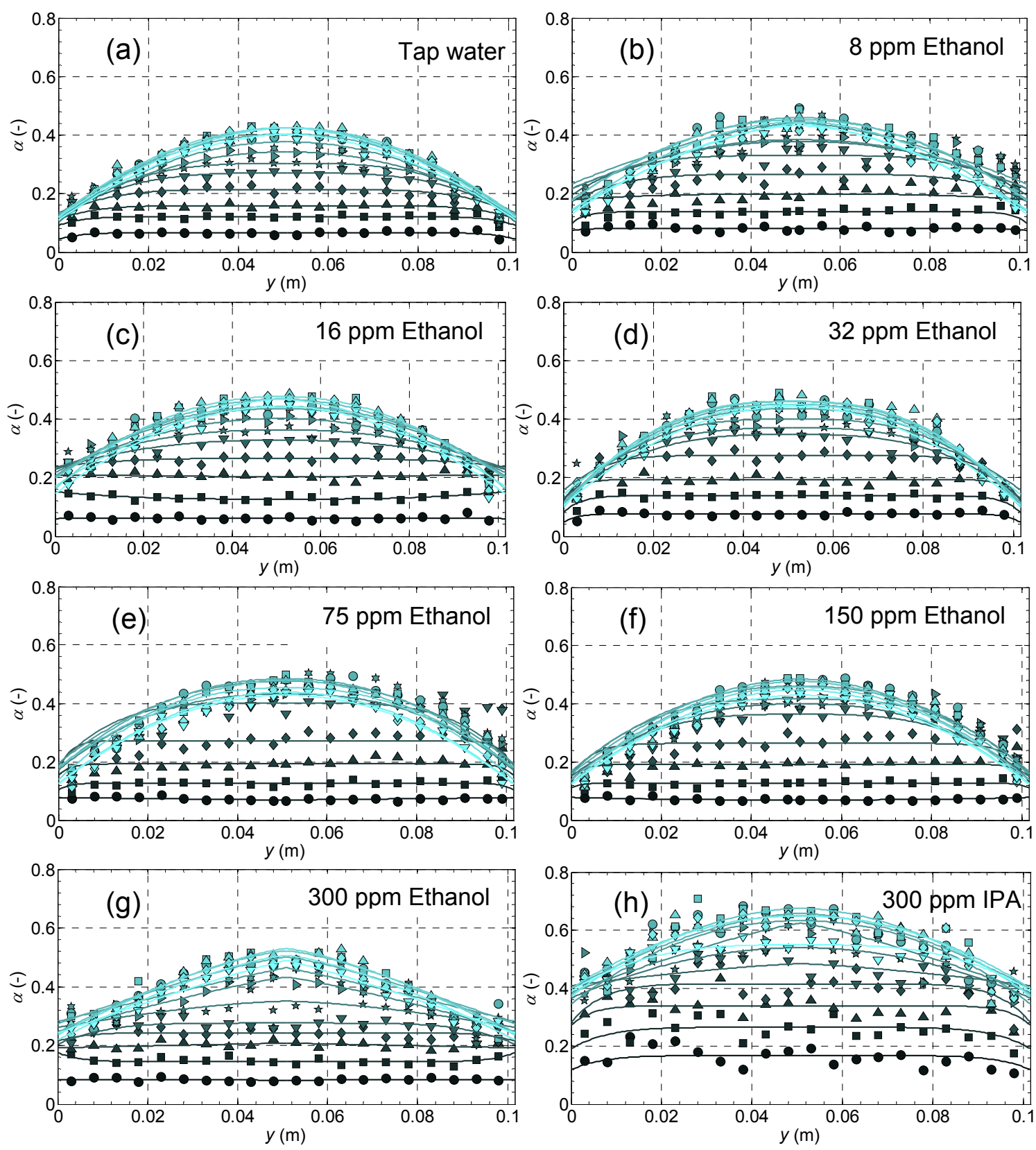

- $0.014 \mathrm{~m} / \mathrm{s} \| 0.026 \mathrm{~m} / \mathrm{s} \Delta 0.039 \mathrm{~m} / \mathrm{s} \forall 0.055 \mathrm{~m} / \mathrm{s} \nabla 0.074 \mathrm{~m} / \mathrm{s}$ - $0.084 \mathrm{~m} / \mathrm{s} \nabla 0.096 \mathrm{~m} / \mathrm{s}$

$\Rightarrow 0.109 \mathrm{~m} / \mathrm{s} \odot 0.120 \mathrm{~m} / \mathrm{s} \square 0.130 \mathrm{~m} / \mathrm{s} \Delta 0.144 \mathrm{~m} / \mathrm{s} \diamond 0.173 \mathrm{~m} / \mathrm{s} \quad \nabla \quad 0.200 \mathrm{~m} / \mathrm{s}$

Figure 3 Profiles of the local gas void fraction with the distance from the wall, $y$, across a diameter of the open tube bubble column, using a porous sparger, tap water and assorted alcohol concentrations. The legend gives the gas superficial velocity. 


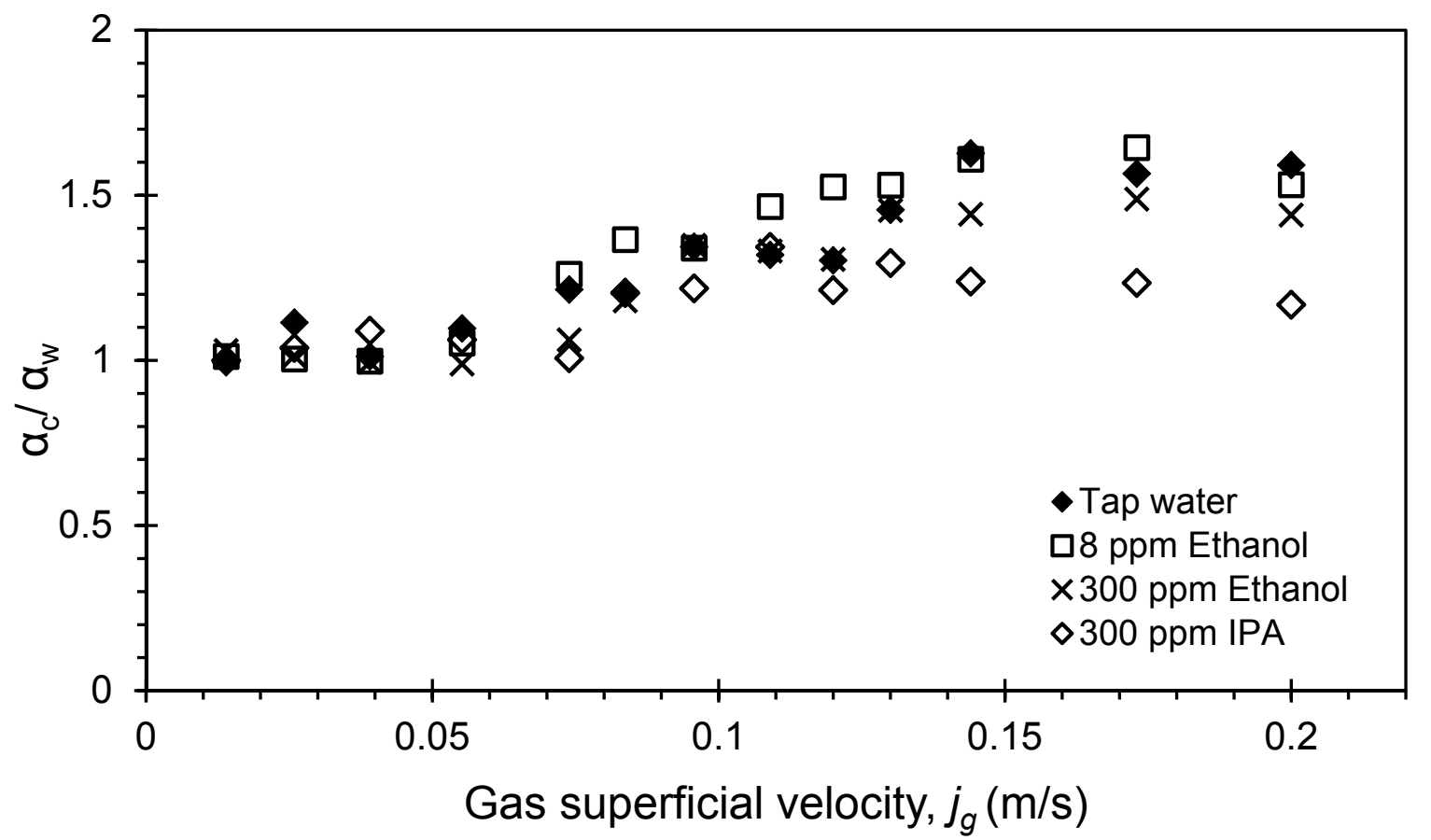

Figure 4 The ratio of the centreline void fraction, $\alpha_{c}$, to the wall void fraction, $\alpha_{w}$, in the OTBC. 

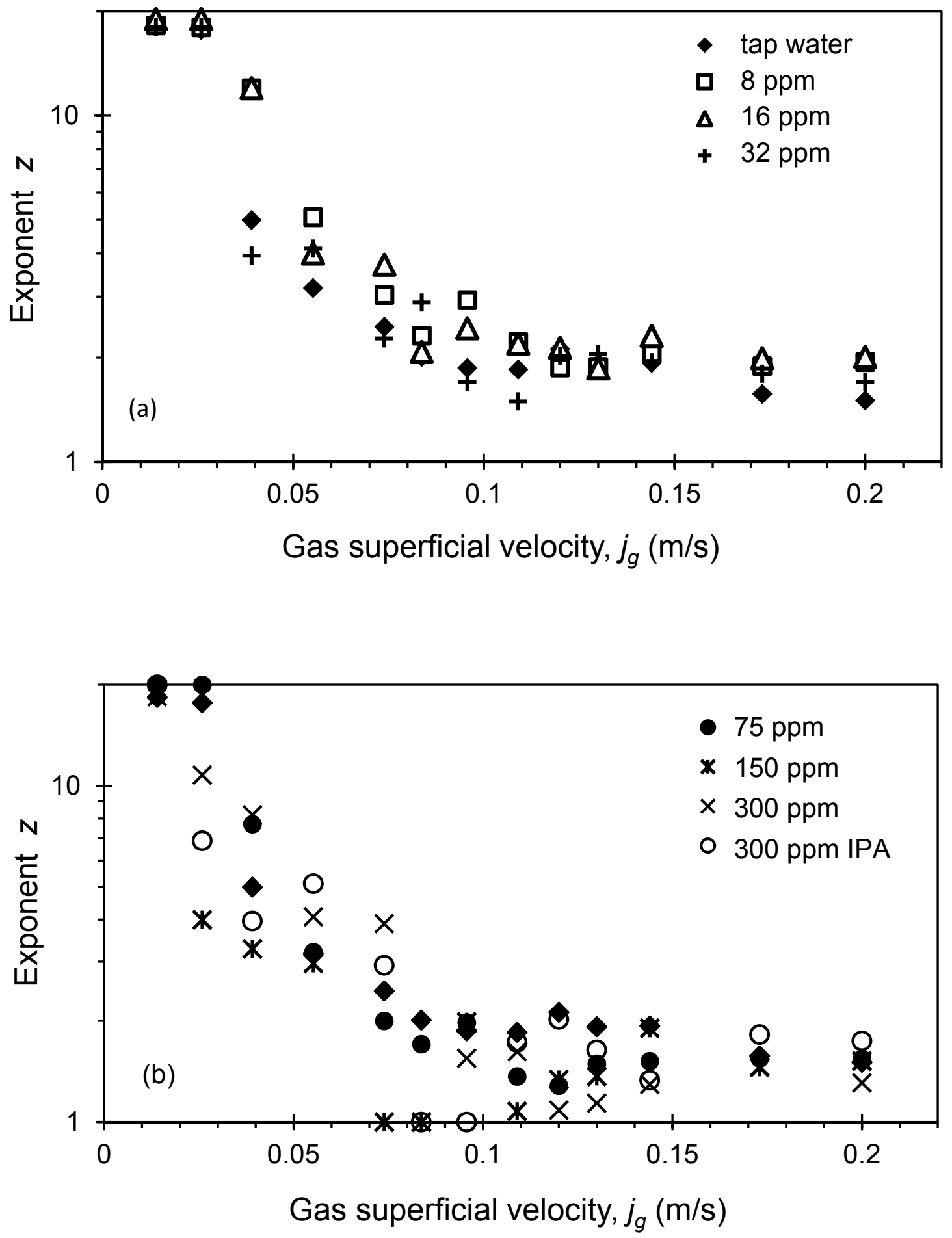

Figure 5 Hibiki and Ishii's (2002) profile exponent $z$ with respect to $j_{g}$ : (a) the tap water and various ethanol concentrations and (b) various ethanol alcohol concentrations and 300 ppm IPA; the experiments were conducted in the OTBC. 


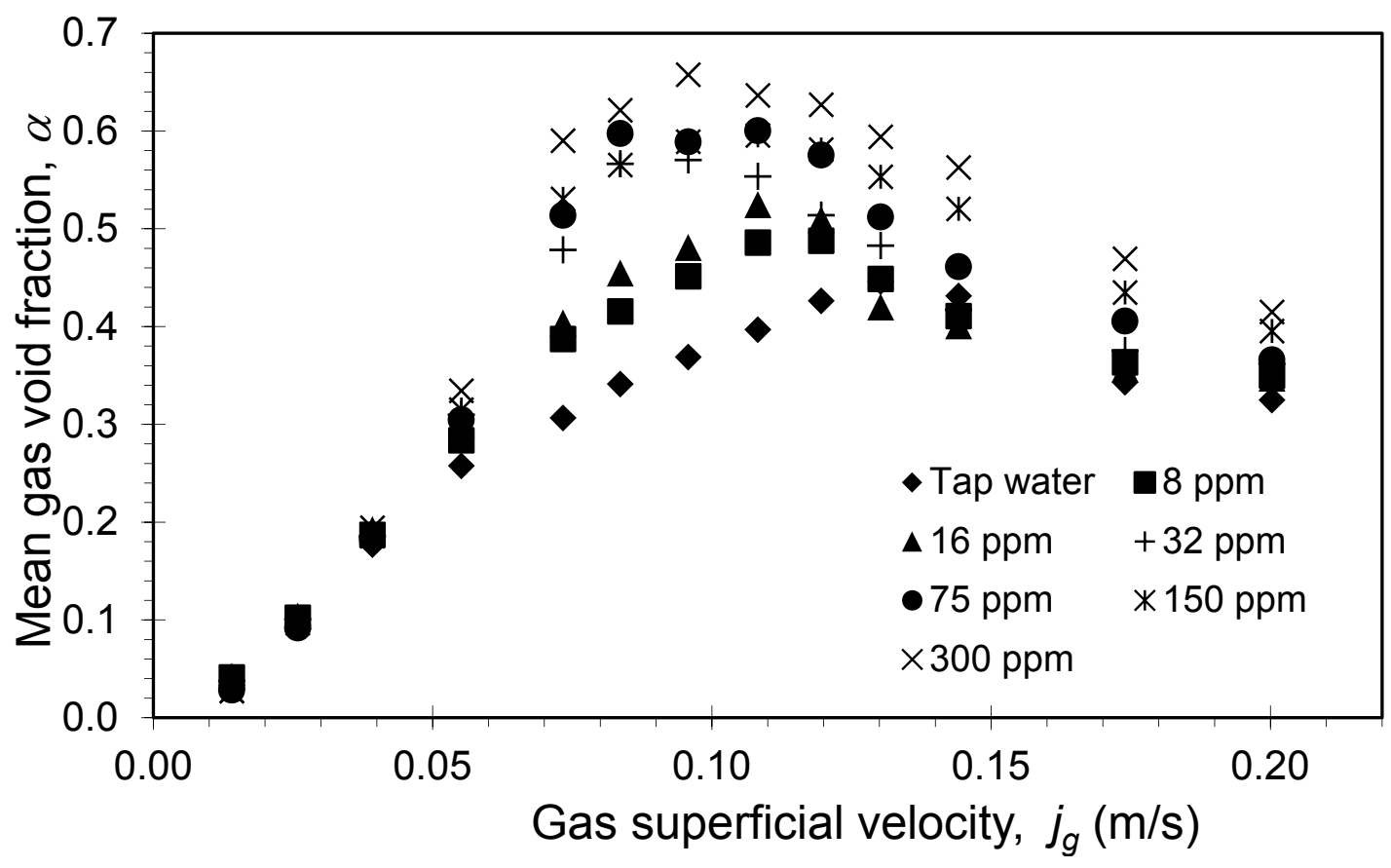

Figure 6 Mean gas void fractions in the OTBC for various ethanol concentrations compared to tap water results, obtained using the aerated level method.

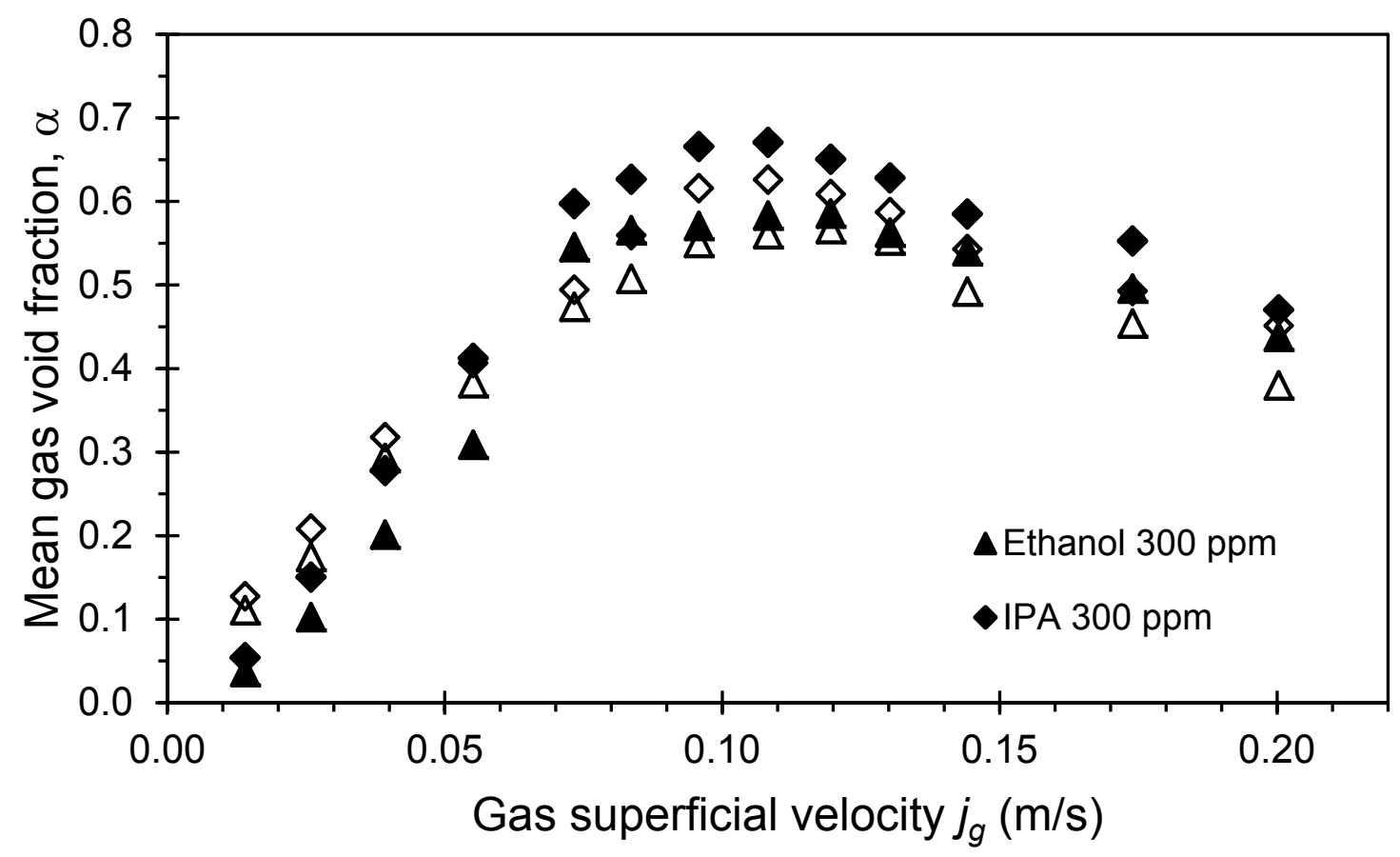

Figure 7 Mean void fractions of ethanol and IPA concentrations at $300 \mathrm{ppm}$ in the OTBC, using the aerated level (filled symbols) and conductivity probe methods (open symbols). 


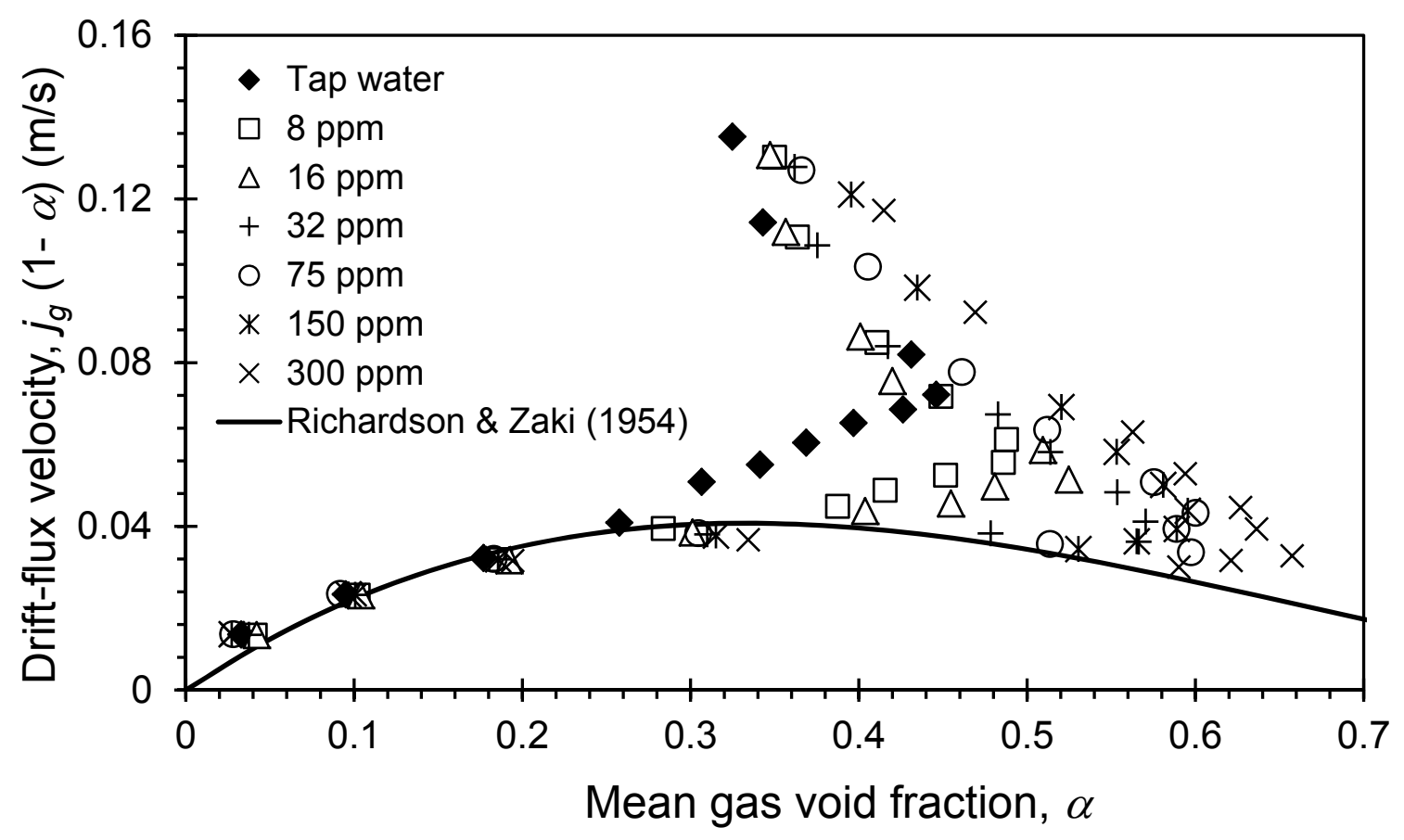

Figure 8 Wallis plot to determine the transition parameters, $\alpha_{\text {trans }}$ and $\left(j_{g}\right)_{\text {trans }}$ for different ethanol concentrations in an OTBC. 

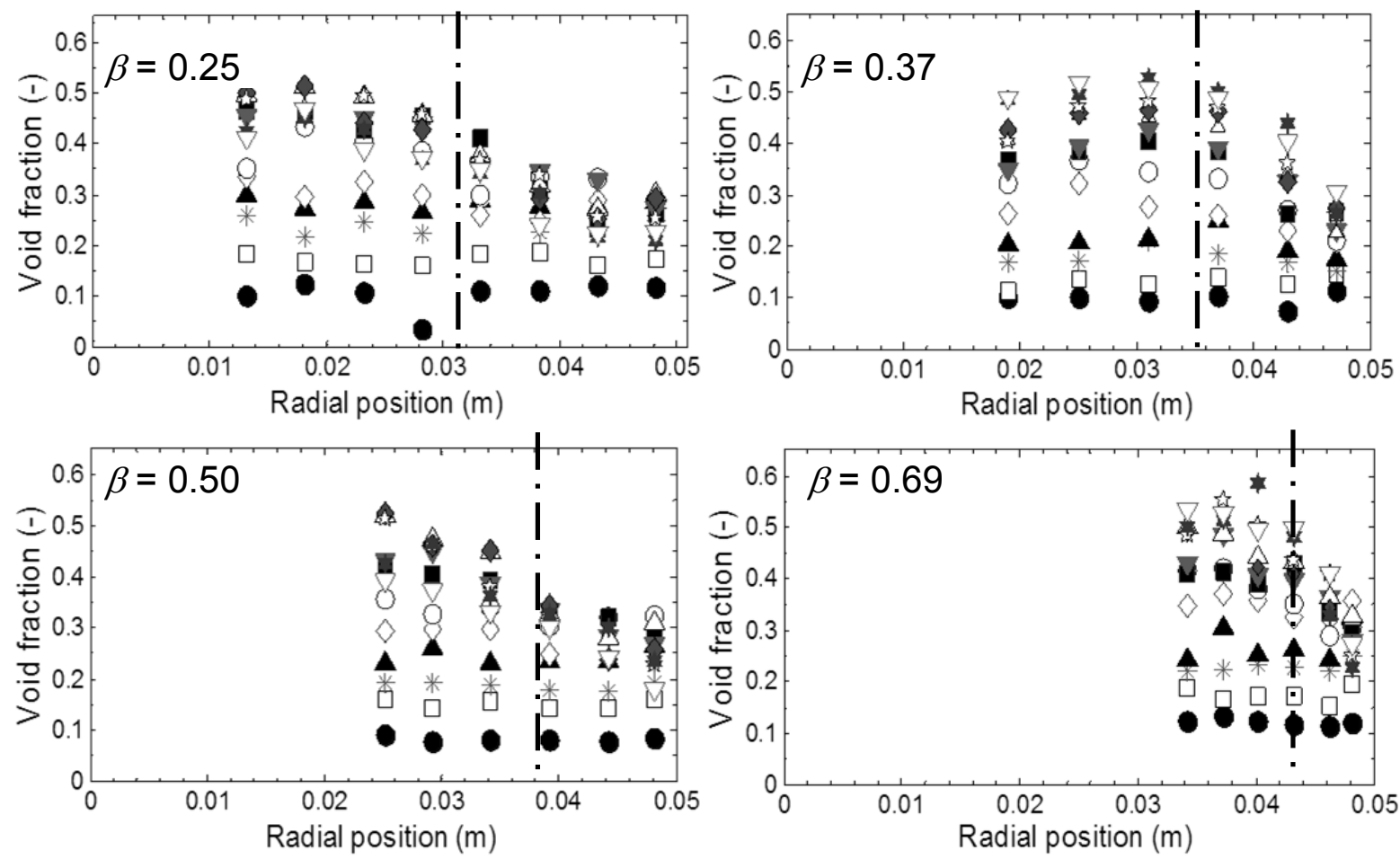

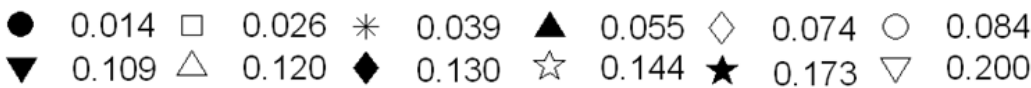

Figure 9 Radial profiles of local gas void fraction for different geometries of the AGBC for 300 ppm ethanol. The vertical dashed line indicates the centreline of the annulus. The legend gives the gas superficial velocity $(\mathrm{m} / \mathrm{s})$. 


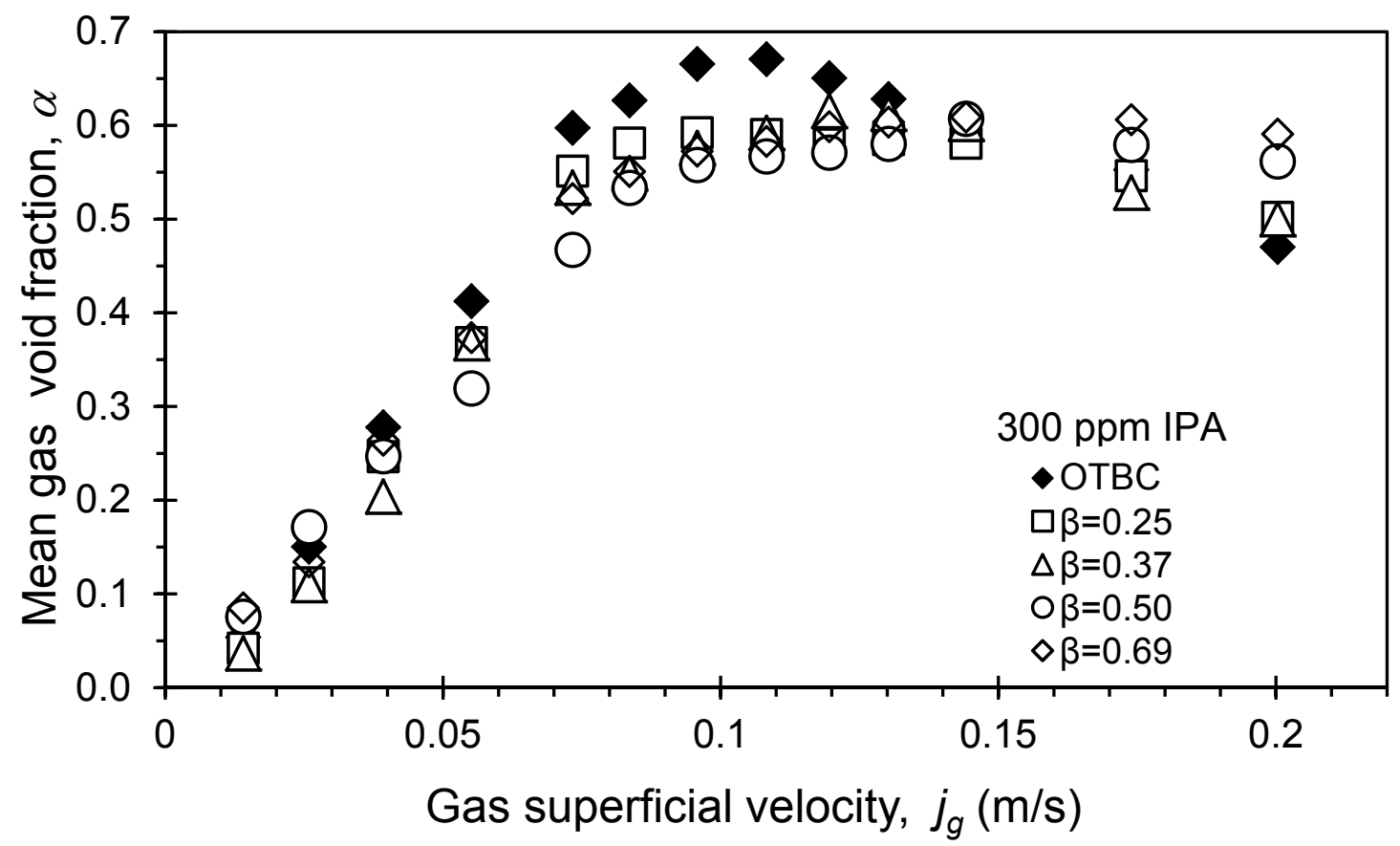

Figure 10 The effects of the AGBC geometry on the mean gas void fraction in a comparison to the OTBC results for 300 ppm IPA, using the aerated level method.

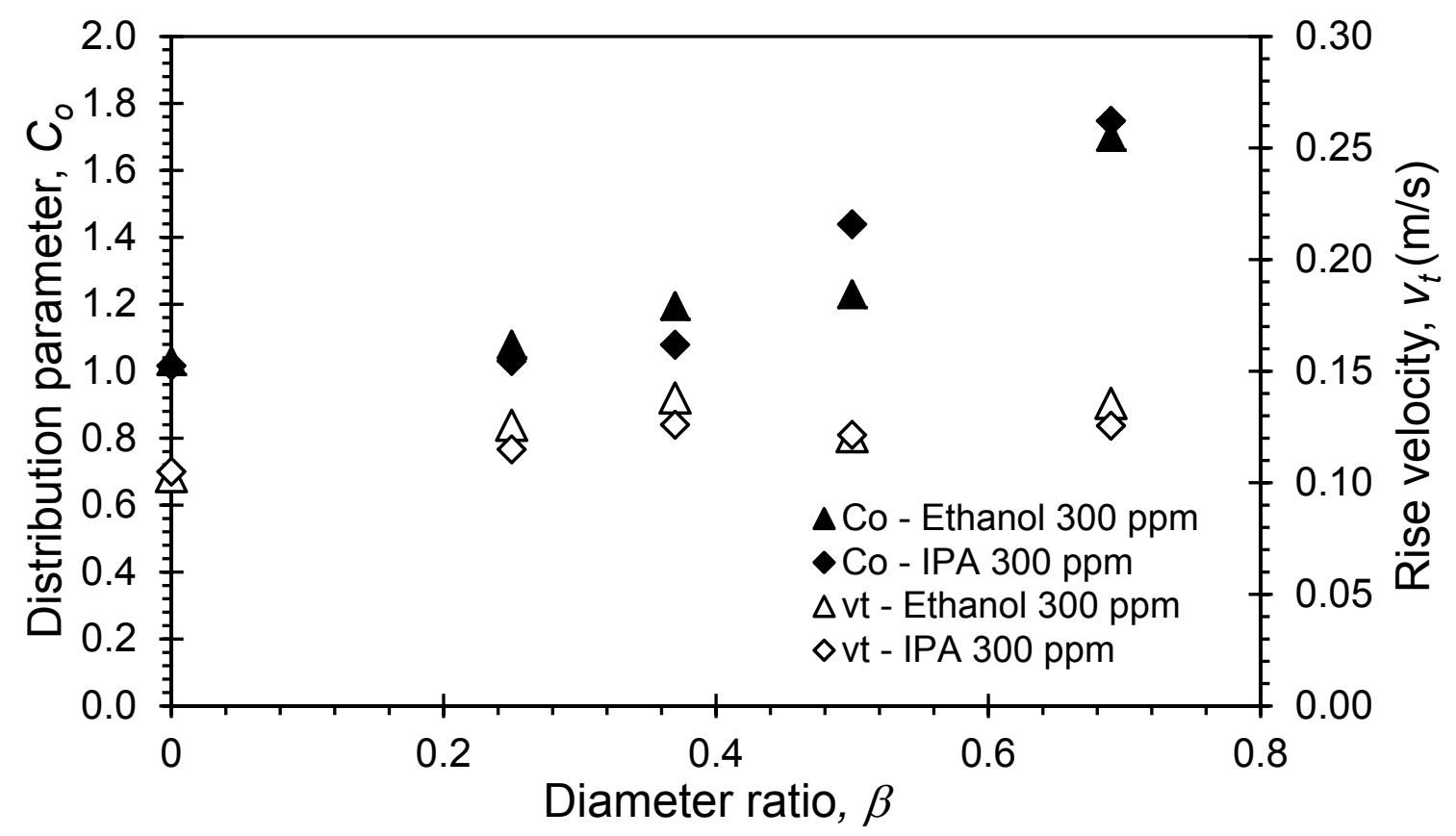

Figure 11 The distribution parameter and the rise velocity with respect to the AGBC diameter ratio for 300 ppm ethanol solution. 


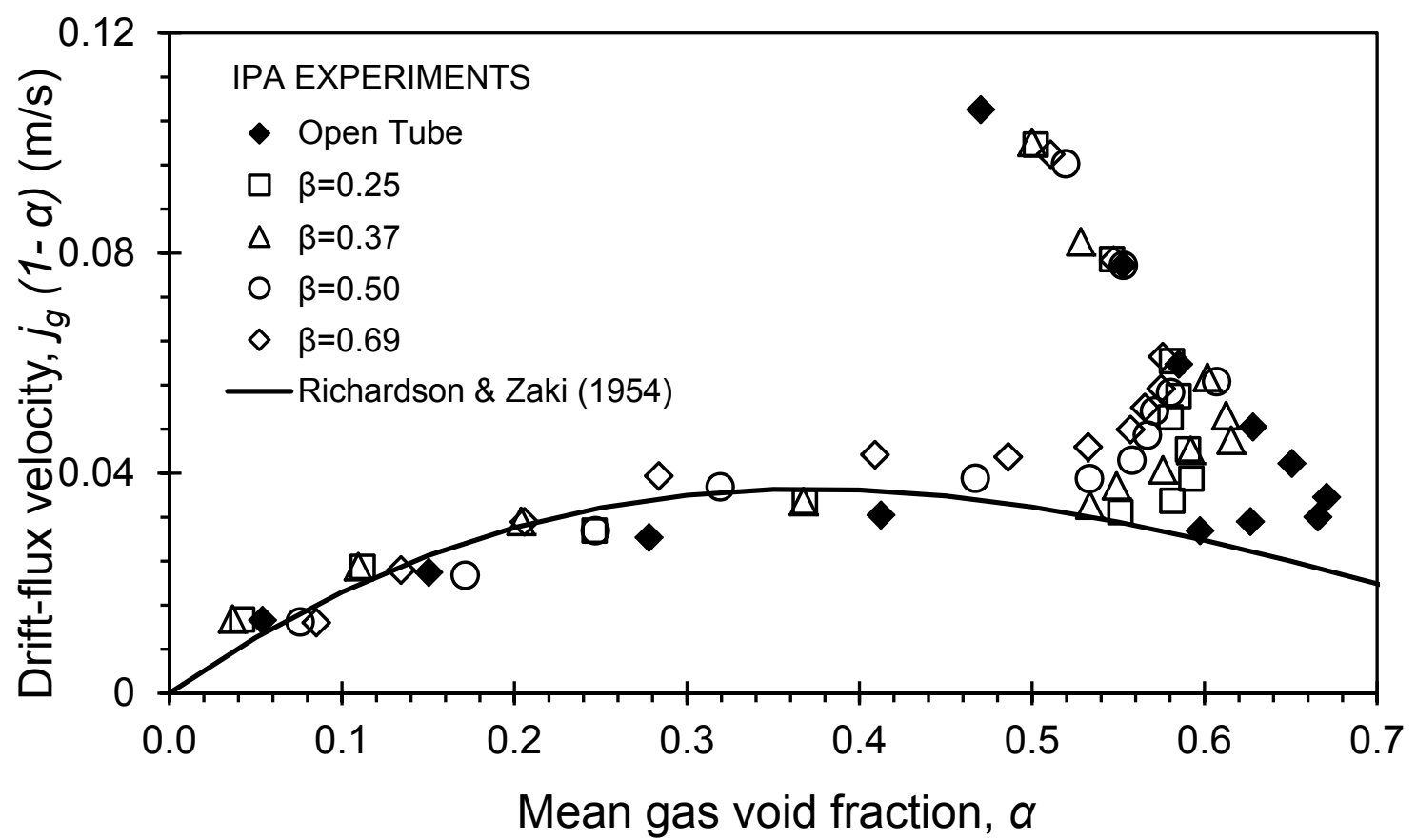

Figure 12 Wallis plot to determine the transition point, $\left(j_{g}\right)_{\text {trans }}$ and $\alpha_{\text {trans }}$ for $300 \mathrm{ppm}$ IPA in the OTBC and various geometries of AGBC. 
Table 1 Alcohol concentrations (by mass) used in the study

\begin{tabular}{lll}
\hline System & Ethanol (ppm) & Isopropanol (ppm) \\
\hline OTBC & $8,16,32,75,150$ and 300 & 300 \\
\hline AGBC & 300 & 300 \\
\hline
\end{tabular}


Table 2 Summary of $\alpha_{\text {trans }}$ and $\left(j_{g}\right)_{\text {trans }}$ for tap water and alcohol aqueous solutions in an OTBC

\begin{tabular}{lll}
\hline Solution & $\left(j_{g}\right)_{\text {trans }}(\mathrm{m} / \mathrm{s})$ & $\alpha_{\text {trans }}$ \\
\hline 0 (tap water) & 0.048 & 0.26 \\
\hline Ethanol $8 \mathrm{ppm}$ & 0.050 & 0.28 \\
\hline Ethanol $16 \mathrm{ppm}$ & 0.053 & 0.31 \\
\hline Ethanol $32 \mathrm{ppm}$ & 0.062 & 0.48 \\
\hline Ethanol $75 \mathrm{ppm}$ & 0.062 & 0.51 \\
\hline Ethanol $150 \mathrm{ppm}$ & 0.062 & 0.53 \\
\hline Ethanol $300 \mathrm{ppm}$ & 0.060 & 0.58 \\
\hline IPA 300 ppm & 0.063 & 0.60 \\
\hline
\end{tabular}


Table 3 Transition point $\alpha_{\text {trans }}$ and $\left(j_{g}\right)_{\text {trans }}$ for tap water and alcohol aqueous solutions in the OTBC and AGBC

\begin{tabular}{ccc|cc|cc}
\hline & \multicolumn{2}{c|}{ Tap water } & \multicolumn{2}{c|}{ Ethanol 300 ppm } & \multicolumn{2}{c}{ IPA 300 ppm } \\
\cline { 2 - 7 } & $\left(j_{g}\right)_{\text {trans }}(\mathrm{m} / \mathrm{s})$ & $\alpha_{\text {trans }}$ & $\left(j_{g}\right)_{\text {trans }}(\mathrm{m} / \mathrm{s})$ & $\alpha_{\text {trans }}$ & $\left(j_{g}\right)_{\text {trans }}(\mathrm{m} / \mathrm{s})$ & $\alpha_{\text {trans }}$ \\
\hline OTBC & 0.048 & 0.26 & 0.063 & 0.60 & 0.060 & 0.58 \\
\hline$\beta=0.25$ & 0.047 & 0.25 & 0.062 & 0.48 & 0.063 & 0.55 \\
\hline$\beta=0.37$ & 0.047 & 0.25 & 0.058 & 0.36 & 0.062 & 0.53 \\
\hline$\beta=0.50$ & 0.047 & 0.25 & 0.056 & 0.34 & 0.049 & 0.32 \\
\hline$\beta=0.69$ & 0.026 & 0.15 & 0.030 & 0.18 & 0.034 & 0.20 \\
\hline
\end{tabular}

